\title{
lodine deficiency disorders still prevalent in China
}

A

t first, Wang Yi felt tired.

Every day the teenaged girl

would struggle to get out of bed and make it to school. Later, it became harder and harder to swallow. Soon after she noticed her neck swelling and eventually her thyroid gland grew so large her neighbours would make fun of her swollen goiter. At the time, she was told that her liver had been damaged and she should put poultices of cabbage and clay on her sore neck.

"My life was changed by it," she says, 15 years later, a high-necked blouse partly covering a jagged scar on her neck. "It disrupted my schooling. I couldn't grow. I couldn't learn when I felt so bad."

As Yi later discovered, her problem was iodine deficiency, requiring years of pain and eventually surgery. During the mid-1990s, it was a condition that affected 720 million Chinese people, according to government reports. It was also estimated at the time that China had more than 7 million people with endemic goiter and more than 200000 people with congenital hypothyroidism.

According to $\mathrm{Mu} \mathrm{Li}$, a senior lecturer at the University of Sydney's School of Public Health in Australia, iodine deficiency remains the most common cause of preventable brain damage and mental disabilities in the world.

It was only in 1995 that the Chinese government made the use of iodized salt compulsory as it pledged to eliminate iodine deficiency disorders by the year 2000 .

China came late to the challenge. Most countries had tackled the problem decades earlier — Canada in 1949 by mandating that iodine be added to table salt to prevent a host of problems, including thyroid problems such as goiter, developmental delays and congenital hypothyroidism. In terms of intelligence, those with iodine deficiency tend to score 10 to 12 points lower on IQ tests as compared to others who aren't deficient.

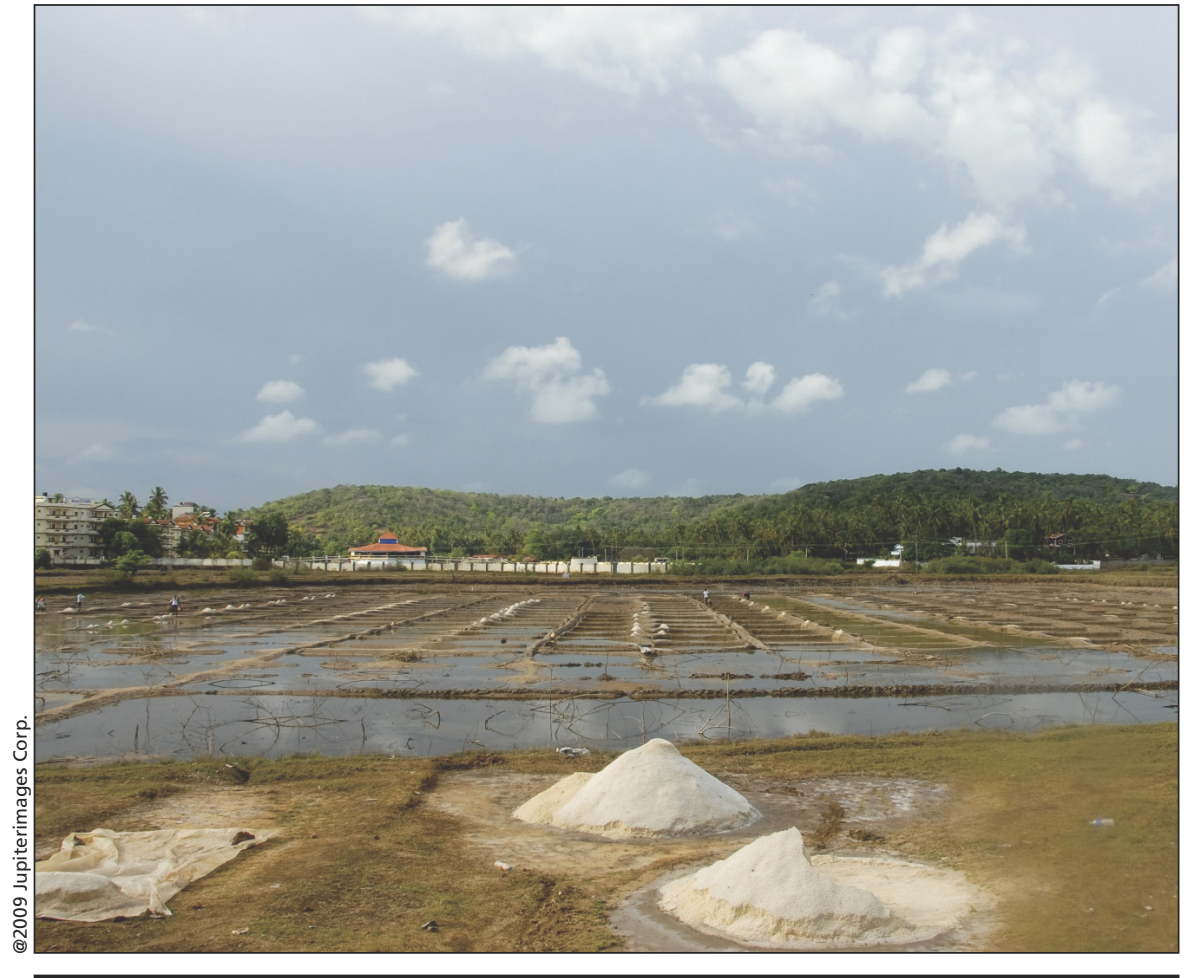

State control over China's salt industry was devolved in the mid-1980s, and the government could not guarantee that iodine was being added to table salt.

The deficiency can also cause miscarriages. Women who carry to term generally have children who suffer from low iodine levels.

Despite the advances and a significant decrease in the number of iodine deficiency related diseases - more than nine years after the Chinese government's 2000 deadline - an estimated 100 million people still face the threat of iodine deficiency.

Yu Nan, a nurse and a friend of Wang Yi, who grew up in the same village in China's Shaanxi province, says iodine deficiency remains a problem in many small villages.

"Our village had many people affected," she says, describing her hometown as a "village full of idiots," in which many people suffer from developmental delays caused by iodine deficiency. "My village was very poor. We didn't know why many people had problems."
Wang Yi's brother was one such sufferer. Yet, she would not have existed had he not had developmental delays. Under China's one-child policy, her parents would have been precluded from having her, were it not that he suffered developmental delays.

"He would sit on the ground and eat mud off the ground," Yi says, making a scooping motion with her hand. "We could not stop him."

At least part of the reason that iodine deficiency remains a problem in China stems from economic reforms of the mid-1980s. State control over the salt industry was devolved and production became decentralized. As more and more small companies popped up, the government could not guarantee that iodine was being added to table salt.

That has, in turn, led to iodine disease deficiencies in the most rural and poverty-stricken regions of the country, particularly in the Xinjiang, Tibet and 
Qinhai provinces, which are primarily populated by ethnic minorities.

Another problem is salt hawked on the black market. The noniodized salt, often lake salt or raw rock salt, is significantly cheaper that iodized salt. The Uighur Muslim population in Xinjiang also tends to use little salt in their cooking. The practice of adding iodine to water supplies has been attempted in the region, as well as providing a "salt allowance" to households of five renminbi per year (approximately 82 cents Canadian) but that doesn't cover off the difference in cost between noniodized and iodized salt.

Reports of those congential hypothryoidism younger than 10 years of age have been reported in the southern region of Xinjiang, where coverage rates are about $30 \%$.

Another problem lies in cultural attitudes. Some residents in Xinjiang feel that the use of iodine in salt is a plot by the Chinese government to keep them sterilized. Other rumours persist that iodized salt causes impotence, AIDS or even seizures.
It remains a major problem, although it is unlikely China will ever slip to the levels of the mid-1990s, in terms of iodine deficiency disorders.

Yet for many, such as Wang Yi, the consequences remain. She still suffers from fatigue and her throat is often sore. "It is a simple solution," she says. "Everyone in China needs to have access [to iodized salt]. There is no excuse." - Katie Lewis, Beijing, China

DOI:10.1503/cmaj.109-3006 